\title{
APROXIMACIÓN HISTÓRICA A LA CREACIÓN PUBLICITARIA COMO OBRA ARTÍSTICA PROTEGIDA
}

\section{APROXIMAÇAO HISTÓRICA PARA A CRIAÇÃO DE PUBLICIDADE COMO UM TRABALHO ARTÍSTICO PROTEGIDA}

\section{HISTORICAL APPROACH TO ADVERTISING CREATION AS A PROTECTED ART WORK}

\author{
José Domingo Portero Lameiro* \\ josedomingo.portero@uca.es
}

RESUMEN: Las primeras creaciones publicitarias se remontan al nacimiento del comercio. Y, aunque inicialmente tan solo mostraban un carácter informativo, pronto adquirieron un marcado sentido persuasivo. También, desde sus orígenes la obra publicitaria ha manifestado una inequívoca representación artística. Al respecto, cabe destacar una primera etapa, durante la Edad Antigua, en la civilización mesopotámica, donde aparece la figura del pregonero al tiempo que comienza la utilización de tablillas de arcilla. Más tarde surgirían los papiros egipcios. La panorámica continua con modestos indicios en Grecia y después en Roma, fruto de la intensificación del comercio en la Edad Media. Con todo, parece que donde mejor se identifica la aludida orientación artística es en el cartelismo como modalidad de obra publicitaria precursora de la publicidad moderna.

PALABRAS CLAVE: obra publicitaria, creación intelectual, obra protegida.

RESUMO: As primeiras criações publicitárias voltam ao nascimento do comércio. $E$, embora inicialmente eles apenas mostrassem uma natureza informativa, logo eles adquiriram um forte sentido persuasivo. Além disso, desde a sua origem, o trabalho publicitário mostrou uma representação artística inequívoca. A este respeito, vale a pena mencionar um primeiro estágio, durante a Idade antiga, na civilização da Mesopotâmia, onde a figura do criador aparece enquanto o uso de comprimidos de argila começa. Mais tarde, os papiros egípcios surgiriam. O panorama continua com indicações modestas na Grécia e mais tarde em Roma, fruto da intensificação do comércio na Idade Média. No entanto, parece que onde a orientação artística acima mencionada é mais bem identificada, é no cartelismo como uma modalidade de trabalho publicitário que é o precursor da publicidade moderna.

PALAVRAS-CHAVE: trabalho publicitário, criação intelectual, trabalho protegido.

ABSTRACT: The first advertising creations date back to the birth of trade. And, although initially showed only informative, they soon became strongly persuasive sense. Also, from its origins advertising work has manifested an unmistakable artistic representation. It is worth noting the first stage, during the Old Ages, in the Mesopotamian civilization, where the figure of the town crier while beginning the use of clay tablets appears. Later they arise Egyptian papyri. Continuous with modest signs in Greece and then in Rome Panoramic result of the intensification of trade in the Middle Ages. However, it seems that better where the aforementioned artistic orientation is identified in the poster as a form of advertising works precursor of modern advertising.

KEY-WORDS: advertising work, intellectual creation, protected work.

\section{Preámbulo}

Sorprende que a pesar de la importancia económica de las agencias publicitarias, cuyo volumen de negocio suele ser superior al de las editoriales, discográficas e, incluso, la todopoderosa industria cinematográfica, no se incluya expresamente la creación publicitaria

\footnotetext{
*Área Historia e Instituciones Económicas -Departamento Economía General -Facultad de Económicas Universidad de Cádiz (Espanha) -Profesor Sustituto Interino (acreditado a Profesor Ayudante Doctor) -Miembro del Grupo de Investigación SEJ-058 del Plan Andaluz de I+D+i (PAIDI)
}

Hist. R., Goiânia, v. 22, n. 2, p. 239-259, mai./ago. 2017 
como obra protegida en el Texto Refundido de la Ley de Propiedad Intelectual ${ }^{1}$ (en adelante LPI), aprobado por el Real Decreto Legislativo 1/1996, de 12 de abril, problema también presente en Derecho comparado, tanto en el entorno continental como en el horizonte anglosajón. Así las cosas, en este artículo pretendo demostrar, a través de un enfoque histórico, el carácter artístico de dicha creación. De tal modo que es admisible que, implícitamente, la obra publicitaria se encuentra al amparo del Derecho de Autor. Con todo, parece oportuno proponer, de lege ferenda, una eventual reforma de la LPI que incluya una referencia expresa a la creación publicitaria (como sí hace, sin embargo, en relación con la obra cinematográfica).

\section{Punto de partida: el concepto de publicidad}

A la luz de lo dispuesto en el art. 2 de la Ley 34/1988, de 11 de noviembre, General de Publicidad² (en adelante LGP), publicidad comercial es "toda forma de comunicación realizada por una persona física o jurídica, pública o privada, en el ejercicio de una actividad comercial, industrial, artesanal o profesional, con el fin de promover de forma directa o indirecta la contratación de bienes muebles o inmuebles, servicios, derechos y obligaciones" $^{3}$. Cabe subrayar la acepción comercial de la publicidad en el texto legal al

\footnotetext{
${ }^{1}$ (BOE núm. 97, de 22 de abril de 1996). Su contenido ha sido modificado por diversas disposiciones, debiendo pues, tenerse en cuenta la Ley 5/1998, de 6 de marzo (BOE núm. 57, de 7 de marzo de 1998), por la que se incorpora al Derecho español la Directiva 96/9/CE, de 11 de marzo de 1996, del Parlamento Europeo y del Consejo, sobre la protección jurídica de las bases de datos; la Ley 1/2000, de 7 de enero (BOE núm. 7, de 8 de enero de 2000), de Enjuiciamiento Civil; la Ley 22/2003, de 9 de julio (BOE núm. 164, de 10 de julio de 2003), Concursal; la Ley 19/2006, de 5 de junio (BOE núm. 134, de 6 de junio de 2006), por la que se amplían los medios de tutela de los derechos de propiedad intelectual e industrial y se establecen normas procesales para facilitar la aplicación de diversos reglamentos comunitarios; la Ley 23/2006, de 7 de julio (BOE núm. 162, de 8 de julio de 2006), por la que se modifica el TRLPI; la Ley 3/2008, de 23 de diciembre (BOE núm. 310, de 25 de diciembre de 2008); la Ley 2/2011, de 5 de marzo (BOE núm. 55, de 5 de marzo de 2011), de Economía Sostenible; y la Ley 21/2014, de 4 de noviembre (BOE núm. 268, de 5 de noviembre de 2014), por la que se modifica el TRLPI.

2 (BOE núm. 274, de 15 de noviembre de 1988). Modificada por: A) la Ley 39/2002, de 28 de octubre, de transposición al ordenamiento jurídico español de diversas directivas comunitarias en materia de protección de los intereses de los consumidores y usuarios (BOE núm. 259, de 29 de octubre de 2002). Se modifican los $\underline{\text { artículos } 6} \underline{25}$ y $\underline{26}$ y se añaden los artículos 6 bis y $\underline{29}$. B) la Ley Orgánica 1/2004, de 28 de diciembre, de Medidas de Protección Integral contra la Violencia de Género (BOE núm. 313, de 29 de diciembre de 2004). Se modifica el artículo 3 , letra a) y se añaden un nuevo apartado 1 bis al art. 25 y una disposición adicional. C) la Ley 29/2009, de 30 de diciembre, por la que se modifica el régimen legal de la competencia desleal y de la publicidad para la mejora de la protección de los consumidores (BOE núm. 315, de 31 de diciembre de 2009). Se modifican el artículo 1 y el título II (artículos $\underline{3}, \underline{4}, \underline{5}$ y $\underline{6}$ ) y se reenumeran los artículos 9 a 24 como artículos 7 a 22.

${ }^{3}$ Este concepto de publicidad comercial sigue la Directiva 84/450/CEE del Consejo, de 10 de septiembre de 1984, relativa a la aproximación de las disposiciones legales, reglamentarias y administrativas de los Estados miembros en materia de publicidad engañosa, publicada en el DOCE núm. L250, de 19 de septiembre de 1984. La norma comunitaria define la publicidad comercial como “(...) toda forma de comunicación realizada en el
} 
configurarla, literalmente, como "toda forma de comunicación (...)" (art. 2 LGP), guardando una clara analogía con los principios del Derecho a la Información proclamados en el art. 20.1.d) CE, al establecer que "Se reconocen y protegen los derechos: (...) A comunicar o recibir libremente información veraz por cualquier medio de difusión (...)”. Si bien es cierto que la LGP se ciñe al ámbito mercantil, aunque en sentido amplio, cuando delimita esa forma de comunicación a la realizada “(...) en el ejercicio de una actividad comercial, industrial, artesanal o profesional (...)" (art. 2 LGP). Y de esta manera -indudablemente- está incluyendo en el ámbito mercantil a cualquier clase de operador económico que ejerza una actividad en el mercado (como en los supuestos de los artesanos, los profesionales de cualquier sector, los clubes deportivos, los artistas de las distintas disciplinas, etc.). En cualquier caso, la publicidad es generalmente una especie de altavoz de la actividad mercantil.

La publicidad, por tanto, consiste en la comunicación ${ }^{4}$ empresarial de un mensaje hacia su target o público objetivo ${ }^{5}$, con el fin de promover la contratación. En este sentido, el

marco de una actividad comercial, industrial, artesanal o liberal con el fin de promover el suministro de bienes o la prestación de servicios, incluidos los bienes inmuebles, los derechos y las obligaciones". En idénticos términos literales se manifiesta el art. 2 de la Directiva 2006/114/CE del Parlamento Europeo y del Consejo, de 11 de diciembre de 2006, sobre publicidad engañosa y publicidad comparativa (versión codificada). Además, la Ley 25/1994, de 12 de julio de 1994, por la que se incorpora al Ordenamiento jurídico español la Directiva 89/552/CEE, sobre la coordinación de disposiciones legales, reglamentarias y administrativas de los Estados miembros relativas al ejercicio de actividades de radiodifusión televisiva (modificada, a su vez, por la Ley 22/1999, de 7 de junio), define en su art. 3.c) Publicidad por televisión: "cualquier forma de mensaje televisado emitido, mediante contraprestación y por encargo de una persona física o jurídica, pública o privada, en relación con una actividad comercial, industrial, artesanal o profesional, con el fin de promover la contratación de bienes muebles o inmuebles o de servicios de cualquier tipo (...)". Consecuentemente, esta definición de publicidad (televisiva) es literalmente coincidente con la contenida en la norma 2 de la Regulación sobre emisión publicitaria de Televisión Española, S.A., (establecida por la Dirección General del ente público Radiotelevisión Española, a la luz de la Resolución que dispuso el 22 de enero de 2001). Por otro lado, la Directiva 2005/29/CE del Parlamento Europeo y del Consejo, de 11 de mayo de 2005, relativa a las prácticas comerciales desleales de las empresas en sus relaciones con los consumidores en el mercado interior (modifica las Directivas 84/450/CEE, 97/7/CE, 98/27/CE y 2002/65/CE, y el Reglamento [CE] núm. 2006/2004 [Directiva sobre las prácticas comerciales desleales]) indica que los Estados miembros no deberán restringir "la libre prestación de servicios ni la libre circulación de mercancías (...)". En definitiva, el objetivo principal de las Directivas Comunitarias es conseguir la armonización de las leyes nacionales reguladoras de la publicidad, dado que se trata de un sector con enorme trascendencia en el funcionamiento del mercado interior europeo, que, por su propia naturaleza, atraviesa las fronteras.

${ }^{4}$ De igual modo lo entiende DE LA CUESTA RUTE, cuando señala que "nadie discute hoy que intrínsecamente la publicidad es comunicación; y, concretamente, comunicación colectiva. (...) Es significativo que en la actualidad se tienda a usar cada vez más la expresión comunicación comercial como sinónimo de publicidad" -Vid. DE LA CUESTA RUTE, J. M. (2002), [op. cit., pp. 27 y 39]-.

${ }^{5}$ La empresa anunciante para determinar de algún modo la partida de audiencia intencional, también denominado público objetivo o target, llevará a cabo (o encargará a un tercero) un estudio de mercado, consistente en una estimación cuantitativa y cualitativa en base a variables sociales, económicas, demográficas, etc. De lo que se trata es de definir cómo sería el receptor óptimo, o destinatario ideal al que va dirigida la 
mensaje publicitario debe ser lo suficientemente atractivo y original para que pueda transmitir la información de un modo también lo suficientemente persuasivo, inclinando la conducta del receptor hacia los productos o servicios que anuncia el emisor. Estos rasgos de originalidad y persuasividad que ha de presentar el mensaje publicitario, lo distinguen de la simple información que se limita a transmitir el conocimiento de meros datos o de hechos de la realidad, por ejemplo la publicidad legal (la registral, la procesal y la judicial). Por ello, la publicidad mercantil, como instrumento de la actividad competitiva de los empresarios u operadores económicos que actúan en el mercado, busca transmitir esa información de un modo exclusivo y original, para influir positivamente en la decisión de compra de los destinatarios.

\section{La creación publicitaria como obra artística}

\subsection{Consideraciones previas}

Es fácil entender que una creación publicitaria ostenta un carácter literario cuando consiste solamente en un texto; o artístico si (como desde tiempos remotos) emplea dibujos, pinturas o fotografías; o musical, con o sin letra; o audiovisual cuando está integrada por elementos literarios y artísticos con la intención de ser difundida por medio del cine o la televisión; también se puede llegar a considerar que una obra publicitaria posee un carácter científico siempre que el texto del anuncio contenga datos o menciones de esta naturaleza, por ejemplo, las cualidades terapéuticas de un medicamento.

Dicho esto, las obras publicitarias son creaciones intelectuales fruto de la mente humana o del intelecto de su autor, perceptibles e idóneas en el tráfico comercial actual, y presentan la naturaleza propia de los bienes inmateriales. Este carácter inmaterial permite distinguir que están compuestas por un corpus mysticum, que es la idea o creación en sí misma, y por un corpus mechanicum o soporte material a través del cual se hace perceptible la idea o creación. Además, como bienes inmateriales se caracterizan por ser susceptibles de apropiación simultánea por un número ilimitado de personas.

Pero esa ideación y elaboración intelectual precisa de un esfuerzo y una dedicación, a veces muy intensos, para llegar a crear una obra publicitaria, por lo que sería injusto que

campaña publicitaria en cuestión (o, en definitiva, el producto -ya sea un bien o un servicio- ofrecido), para $-a$ posteriori- lograr identificar esos rasgos o ese perfil en el grueso de la audiencia o población expuesta al anuncio. A mayor exactitud o precisión en la estimación cualitativa y cuantitativa, mejor resultado conseguirá la publicidad, o visto de otro modo, más eficaz será ésta. 
alguien pretendiera copiarla o imitarla, con la intención de aprovecharse no solo de ese esfuerzo ajeno, sino también del prestigio de su creador o de la reputación del producto copiado. Esta preocupación justifica la existencia de normas que se encargan de dotar de protección a las creaciones publicitarias, y así evitar su apropiación indebida por parte de otras personas ${ }^{6}$.

La actividad intelectual o creativa encaminada a la consecución de una obra de esta naturaleza se basa en las técnicas o estrategias del marketing. Se considerará un excelente colaborador del empresario o anunciante ${ }^{7}$ al autor/agencia o publicista que mejor convenza al consumidor potencial y consiga que éste adquiera los bienes, o solicite los servicios que su anunciante o financiador ofrezca en el mercado.

\subsection{Antecedentes históricos}

\subsubsection{Las primitivas obras publicitarias}

A lo largo de los tiempos, la publicidad evoluciona con los cambios sociales, económicos y tecnológicos. Si bien, inicialmente solo ostentaba un carácter informativo ${ }^{8}$, posteriormente irá logrando el aspecto persuasivo que predomina en la actualidad.

\footnotetext{
${ }^{6}$ A su vez, las agencias publicitarias durante la realización del encargo efectuado por su cliente (el anunciante), se esfuerzan en proteger su trabajo evitando la posibilidad de copia o plagio de éste. Por su parte, la agencia de programación creativa multiplataforma Aldea.net ofrece el método de trabajo crossmedia, consistente en que "primero se parte del mensaje y después se seleccionan los soportes donde se va a emitir (...). El medio [de difusión] es quien se amolda al mensaje (...)". Es de suponer que el medio de difusión empleado condicionará sobremanera el rating o porcentaje de audiencia efectiva. Usualmente la obra publicitaria está formada por varias creaciones intelectuales (imágenes, fotografías, ilustraciones, jingles o sintonías musicales, etc.), creadas expresamente a tal objeto, si bien, es cierto que existen otros procedimientos para conseguir los contenidos de la futura obra. En este sentido, a través de la acción del denominado royalty free, se adquieren las creaciones necesarias para conformar la obra publicitaria, pero, se trata de obras no exclusivas, con lo cual existe el inconveniente de que sean utilizadas por otras personas. A este respecto, las agencias proponen a sus clientes (los anunciantes), la incorporación a la obra publicitaria encargada por éstos, de creaciones que ostenten derechos restringidos, en definitiva, de uso exclusivo (el handicap suele ser el elevado precio a satisfacer para su adquisición) -Fuente: Aldea.net (2010)-.

7 La LGP en su art. 8 considera anunciante a "la persona natural o jurídica en cuyo interés se realiza la publicidad". El anunciante es quien realiza el encargo publicitario obligándose a retribuirlo, normalmente, a una agencia de publicidad. Según el mismo precepto, "son agencias de publicidad las personas naturales o jurídicas que se dediquen profesionalmente y de manera organizada a crear, preparar, programar o ejecutar publicidad por cuenta de un anunciante".

8 Piénsese en la labor de los Scriptores romanos, quienes se dedicaban a escribir o dibujar en letreros o carteles que posteriormente colocaban en lugares concurridos. En mi opinión, es muy atrevido considerar dicha labor como precursora de la desempeñada por los actuales publicistas autónomos o freelance, pues las obras de los primeros solo ostentaban carácter informativo. A veces, por medio de iconos o insignias se facilitaba la identificación de ciertos negocios. En este sentido, una piña colgada del marco de una puerta identificaba cualquier taberna, pues sugería la utilización de la resina que recubría los barriles de vino con los que contaban.
} 
Cronológicamente, al hablar de los inicios de este movimiento creativo no hay unanimidad, en cualquier caso, a mi entender se distinguen dos etapas:

En primer lugar, una fase caracterizada por el tímido nacimiento de la publicidad paralelo al del comercio, durante la Edad Antigua, en la civilización mesopotámica. En este momento aparece la figura del pregonero y comienza la utilización de tablillas de arcilla, incluso con fines propagandísticos. Más tarde surgirían los papiros egipcios.

En segundo lugar, la panorámica continúa con modestos indicios publicitarios en Grecia y después en Roma, fruto de la intensificación del comercio en la Edad Media. Aunque a grandes rasgos, las técnicas siguen siendo parecidas, lo cierto es que la figura del pregonero se consolida.

\subsubsection{Primera etapa: Código Hammurabi y tablillas de arcilla}

En la antigua civilización mesopotámica ${ }^{9}$, y durante el gobierno del rey Hammurabi $^{10}$, Babilonia se convirtió en el principal núcleo comercial del Asia occidental. En consecuencia, se hizo necesaria la publicidad, y aparecen las primeras obras publicitarias, de un lado, a través de la figura del pregonero y, de otro lado, por medio de las primitivas fotocopias u octavillas materializadas en tablillas de arcilla.

Atendiendo a disquisiciones legales, hacia el año 1692 a. C. (según cronología breve) o, en el año 1760 a. C. (según cronología media), el insigne monarca decidió unificar la regulación de su vasto imperio ordenando que el conjunto de leyes por las que se regían habían de ser escritas ${ }^{11}$. Así nació el Código Hammurabi, conocido popularmente por mezclar los principios establecidos por la Lex talionis. El prólogo enaltece a los dioses por el régimen jurídico conferido, pues como en cualquiera de las antiguas culturas del Próximo Oriente, las leyes se consideraban sagradas. Además, en la Edad Antigua las legislaciones escritas en piedra se concebían inalterables.

\footnotetext{
${ }^{9}$ Mesopotamia o región entre ríos, en concreto entre el Tigris y el Eúfrates, es la zona geográfica en la que actualmente se sitúan los países de Irak, casi en su totalidad, así como unas porciones de Siria y Turquía.

${ }^{10}$ El poderoso rey Hammurabi (1722-1686 a. C. según cronología breve o 1792-1750 a. C. según cronología media) fue el sexto monarca de la dinastía de Babilonia. Fuente: Historia Clásica (2007).

${ }^{11}$ Antes de la llegada al trono de Hammurabi, los sacerdotes ejercían como jueces. Además, sin ley escrita, ésta se aplicaba de forma diferente, produciendo las consecuentes injusticias. Posteriormente, el rey encomendó esta labor a nuevos funcionarios a los que dirigiría a su antojo. Sin embargo, pese a que el Código Hammurabi supuso un avance en cuanto a la distinción de la existencia o no de intencionalidad en los delitos, en las penas aplicables a esas acciones jugaba un papel principal tanto la clase social del acusado, como la del demandante.
} 
El Código, en lengua acadia y en escritura cuneiforme ${ }^{12}$, estaba constituido por casi trescientas leyes y edictos que regulan la propiedad, el trabajo, el comercio, la actividad publicitaria, los préstamos, los alquileres, las herencias, los impuestos, etc. Los preceptos jurídicos se ilustran más como casos particulares que como normas generales. Asimismo, para entender lo que realmente supuso el Código de Hammurabi es necesario consultar unas cartas del monarca, escritas sobre tablillas de arcilla, en las que el propio soberano dictaminaba ciertas sentencias ante particulares casos.

Actualmente instalado en la sala Babilónica del Museo del Louvre (París), el Código Hammurabi $^{13}$, se presenta tallado en un enorme bloque de basalto de unos dos metros y medio de altura por casi dos metros de anchura, consta de 52 columnas, 24 en la parte delantera de la estela y 28 en la posterior, que suman un total de 3600 líneas.

Ciertamente, dada la gran envergadura de este enigmático tabique, parece válido nombrarlo como la versión antigua de un moderno panel publicitario. En este sentido, he de subrayar que este monumental símbolo presenta, a mi entender, un carácter publicitario, al menos latu sensu, en tanto que pretende persuadir del cumplimiento de los postulados que comunica.

De otro lado, al hablar de la obra publicitaria primitiva strictu sensu, téngase presente que el anuncio publicitario más antiguo se ha encontrado en la localidad de Tebas (Egipto) y, según constatan ciertos estudios, data del año 1000 a. C. Se trata de un papiro encargado por un artesano del gremio textil, y describe la buena calidad del género ofrecido por aquél. Actualmente se halla expuesto en el British Museum de Londres ${ }^{14}$.

\subsubsection{Segunda etapa: Kerux en Grecia y Praeco en Roma}

\footnotetext{
${ }^{12}$ Los inventores más célebres de Mesopotamia fueron los sumerios, a quienes se atribuye, entre otras cosas, la invención de la escritura cuneiforme o, en forma de cuña, desarrollada mucho antes que los jeroglíficos egipcios, en concreto, fechada alrededor del año 3100 a. C. Hito que marca el término de la Prehistoria y el inicio de la Historia. Fuente: Histórico Digital (2010). A mayor abundamiento, vid. WALKER, C. B. C. (2004), Cuneiform, British Museum Press, Londres.

${ }^{13}$ En sus inicios se ubicó en el Templo de Sippar, aunque ciertos estudios sugieren que numerosos ejemplares idénticos se dispusieron a lo largo y ancho del reino -Fuente: Historiang (2010)-. De forma unánime, los historiadores apuntan que a causa de las diferentes invasiones de Babilonia, hacia el año 1200 a. C. el Código se trasladó a la ciudad de Susa (en el antiguo reino de Elam), actualmente en la región del Jucestán (al sur de Irán), donde se localizó, a finales de 1901, por la expedición dirigida por el arqueólogo francés Jacques de Morgan Fuente: Biografías y Vidas (2010)-.

${ }^{14}$ Fuente: Publicidad Idóneos (2012).
} 
Los comienzos de la publicidad en la civilización griega ${ }^{15}$ se remontan a la época del manejo del denominado Kerux o pregón en Grecia, como procedimiento de comunicación de los mensajes públicos, sobre todo los relacionados con la religión y con la política. Más tarde, en Roma, se utilizaría el llamado Praeco o bando, para la difusión de la información pertinente cuando la actividad comercial comenzaba ya a intensificarse, fruto de la proliferación de los designados Mercatus ${ }^{16}$, entendidos por entonces como lugares físicos donde se asentaban para ofrecer sus productos las primeras tiendas artesanas y ambulantes.

Por tanto, en el período de la Edad Media se extiende la figura del pregonero ${ }^{17}$, quien, en sus inicios, anunciaba la llegada de los barcos cargados de vino y especias. Por su parte, los diversos gremios profesionales trataban de dar a conocer sus bienes o servicios en enseñas de madera o emblemas de hierro. Ciertamente, en una famosa cita de Platón ya se apreciaban indicios, al menos, de comunicación comercial, cuando el prestigioso sofista indica de forma filosófica, "hemos de evitar-amigo mío- que el tendero nos engañe cuando alaba lo que vende".

\subsubsection{El cartelismo como modalidad de obra publicitaria precursora de la publicidad moderna}

Con el transcurso del tiempo, la actividad mercantil se intensificaría, dando lugar a un aumento de la competencia $y$, consecuentemente, las obras publicitarias se perfeccionarían. Poco a poco llegarían los primeros carteles ${ }^{18}$, cuyo objetivo era tan solo informar ${ }^{19}$, dado que no pretendían influir en la capacidad de decisión del consumidor como ocurriría si ostentaran carácter publicitario. Ciertamente, a pesar de su sencillez, pues se trata de un anuncio a modo de póster colocado generalmente en la calle al objeto de

\footnotetext{
15 Incluso, es conocido que los orígenes de la publicidad comparativa se atribuyen al célebre Vaso Ateniense, el cual data del siglo V a. C. Fuente: Monografías.com (2012).

${ }^{16}$ Si bien es cierto, los mercados ya existían en Grecia y se denominaban Arinas. Fuente: HCivilizaciones (2011).

17 Homólogo del Heraldo griego y del Praecon romano. Ciertos estudios constatan que ambas figuras y, en definitiva, los pregoneros de entonces carecían de una buena consideración social -Fuente: Imperio Romano (2012)-. Hubo que esperar hasta el siglo XII para que en florecientes ciudades como París, los pregoneros y los juglares comenzaran a gozar de una considerable reputación. Pues, debido al elevado grado de analfabetismo, la expresión oral se postulaba como el principal medio de comunicación -Fuente: Arte versus Publicidad (2010)-.

${ }^{18}$ Nótese que nos referimos a los carteles como concreta forma de creación intelectual publicitaria. Es decir, con el paso del tiempo, las modalidades de anuncios evolucionaron y, mientras el pregón perdía frecuencia, nacía el cartel.

${ }^{19}$ Aunque inicialmente la mayoría de los carteles presentaban contenidos políticos o religiosos, ciertamente circulaban in crescendo los de auténtico orden comercial, tanto de productos (en gran medida outputs de botica), como de servicios (relacionados con el ocio de la época: fiestas y espectáculos).
} 
incentivar su visibilidad, el cartel propagandístico es, posiblemente, la creación intelectual que mejor adhiere la publicidad al arte ${ }^{20}$.

Originariamente los carteles se confeccionaban por medio de la xilografía, técnica consistente en realizar incisiones con una gubia sobre un tablón de madera. Pero, sin duda, el momento más trascendental para este tipo de obras fue la invención de la imprenta ${ }^{21}$ por Güttemberg hacia 1440. Como es de suponer, la calidad de los primeros carteles impresos era mediocre, sin embargo cabe destacar la gran aportación de los artistas, quienes aplicaron su particular estilo a las obras que crearon.

Llegados a este punto, es preciso distinguir el cartel propiamente dicho del cartel ilustrado, así como del cartel artístico. Hacia 1480 en Inglaterra ${ }^{22}$ vio la luz el primer cartel, obra de William Caxton, quien contaba las excelencias de ciertas aguas termales. Poco después, en 1482, Francia acogió el primer cartel ilustrado de la Historia, elaborado por Jean Du Pre. Posteriormente, en 1518, Alemania asistió a la creación del primer cartel artístico, el cual anunciaba un juego de lotería, concepción del pintor Albretch Altdorfer, discípulo del prestigioso Alberto Durero.

Usualmente, se acepta que el cartelismo es el precursor de la publicidad moderna en tanto propició el nacimiento de las agencias de publicidad ${ }^{23}$. A este respecto, en general se admite que Estados Unidos es el país donde primero se desarrolla la publicidad moderna, atribuyéndose a Volney $B$. Palmer la inauguración de la primera oficina como agente publicitario en Philadelphia en 1841 (paralelamente en Francia comenzaba la época de esplendor del cartelismo). Sin embargo, lo cierto es que ya en 1611 y 1612 , respectivamente,

\footnotetext{
${ }^{20}$ Sin olvidar que cualquier obra de índole publicitario es como tal una creación intelectual, al tiempo que ostenta un carácter artístico, literario o, incluso, científico.

${ }^{21}$ La aportación de Güttemberg precisaba de la técnica de la tipografía que, a pesar de su lentitud, facilitaba la impresión de textos con un hueco en el centro sobre el que colocar una ilustración. A principios del siglo XIX la litografía, por medio de planchas de pizarra caliza sobre las que se dibuja, permitía rapidez. Poco después, a mediados del mismo siglo, Firmin Guillot inventó una nueva técnica denominada guillotage, utilizando una plancha de zinc -Fuente: Arte versus Publicidad (2010)-.

${ }^{22}$ Cabe anotar que en 1614, se promulgó en Inglaterra una Ley que normalizaba el tamaño y la distancia desde el suelo de los carteles, pues -a veces- dificultaban el libre tránsito de personas a caballo.

${ }^{23}$ Es sabido que inicialmente surge la figura del agente de publicidad quien se encarga de buscar financiación para la prensa. Posteriormente, a principios del siglo XX, las agencias estudian con mayor profundidad el mercado al objeto de elegir el medio idóneo y el soporte óptimo donde publicar sus anuncios.
} 
aparecieron la primera oficina publicitaria en Londres y la primera agencia publicitaria ${ }^{24}$ en París, al tiempo que conocimos el primer precedente de la publicidad a domicilio ${ }^{25}$.

Posteriormente, también supuso un impulso muy importante para el cartelismo y, en definitiva, para la publicidad, la intensificación del comercio, fruto del comienzo de la Revolución Industrial (a finales del siglo XVIII), donde se apostó por los sistemas de producción en serie y aumentó el consumo.

A continuación, en el siglo XIX, la sucesión de diferentes acontecimientos hizo posible que se fuera forjando una nueva sociedad, cuya manera de pensar y actuar era distinta a la tradicional. El progresivo aumento de la actividad económica y el espíritu capitalista supusieron, en gran medida, los factores que suscitaron el impulso de la publicidad ${ }^{26}$.

La todopoderosa publicidad es inherente al sistema económico capitalista ${ }^{27}$, que es el óptimo (en cuanto a eficiencia se refiere) ${ }^{28}$. En un sistema económico comunista $^{29}$, donde abundan los monopolios ${ }^{30}$, la publicidad (comercial) carece de sentido, ya que no existe libre

\footnotetext{
${ }^{24}$ En 1612 el visionario francés Renaudot fundó en París la primera agencia publicitaria de la historia. Fuente: Time Rime (2010).

${ }^{25}$ También en el París de 1612 Renaudot inauguró el Bureau d'Adresses desde donde editada un periódico de anuncios por palabras bautizado como Journal General d'Affiches, considerado antecedente del buzoneo, pues se repartía a domicilio. Fuente: Ministerio de Educación y Ciencia (2010).

${ }^{26}$ En la segunda mitad del siglo XIX se desarrolla la marca tal y como la conocemos hoy en día, como garantía de calidad, algunos ejemplos son: Campbell's (1869), Levi's Strauss (1873), Kellogg's (1884), Coca-Cola (1886). En definitiva, para la clase media, cada vez más numerosa, la marca pretende ofrecer una identidad a sus consumidores. Fuente: Historia Publicidad (2007).

27 Según TAMAMES GÓMEZ, R. (1989), Diccionario de Economía, 4a ed., Alianza, Madrid, [op. cit., p. 59], capitalismo es el sistema económico caracterizado por “(...) la propiedad privada de los bienes de producción (...)", aunque en mi opinión, en lugar de bienes, sería más correcto utilizar la expresión factores de producción, refiriéndonos a "tierra, trabajo y capital", ya utilizados por el economista de la denominada Escuela Clásica, Adam Smith, al definir la Teoría de la Producción.

${ }^{28} \mathrm{Y}$ ello, en opinión de los economistas de la corriente del marxismo (a su vez, detractores del capitalismo), aunque sea a costa de que el empresario, para rellenar su partida de beneficios, se apropie de una parte o plusvalor del salario de sus trabajadores (quienes están ofreciendo a su empleador -simbólicamente- algo inenajenable: su propia vida). Lo cierto es que la publicidad genera importantes efectos sobre la Economía y la Sociedad, de modo que activa la demanda, aumenta la oferta, estimula la competencia y ofrece información.

${ }^{29}$ Según TAMAMES GÓMEZ, R. (1989), Diccionario de Economía, 4a ed., Alianza, Madrid, [op. cit., p. 84], comunismo es el sistema económico "por el cual se aspira a abolir el derecho de propiedad privada de los bienes de producción, para suprimir las diferencias de clases y establecer la dictadura del proletariado (...)". De otro lado, tal y como expresó Winston Churchill, premio Nobel de Literatura en 1953, "el comunismo es la filosofía del fracaso, el credo de la ignorancia, y el evangelio de la envidia. Su única e inherente virtud es la distribución equitativa de la miseria". A mayor abundamiento, vid. "Frases demoledoras de Winston Churchill sobre el socialismo, los impuestos y la memoria histórica" publicado en el periódico Navarraconfidencial.com del día 30 de noviembre de 2011.

30 Según TAMAMES GÓMEZ, R. (1989), Diccionario de Economía, 4a ed., Alianza, Madrid, [op. cit., p. 237], monopolio es una “(...) forma concreta de mercado en el que sólo existe un ofertante, que por su situación de
} 
competencia entre quienes concurren en el mercado y -ciertamente- ante una situación de ausencia de competencia o lucha entre los operadores económicos, es utópico hablar de un mercado eficiente. Por el contrario, en el capitalismo o economía de mercado y, en definitiva, en un Estado libre, los ciudadanos cuentan con unos derechos fundamentales como la libertad de empresa (arts. 38 y $53.1 \mathrm{CE}$ ), que ya estaba presente en el CCom de 1885, donde también se proclamaba el principio de libertad profesional. Pues bien, las personas convertidas en empresarios, tras ejercer tales derechos esenciales, hacen surgir la competencia ${ }^{31}$ y, a la postre, la eficiencia del mercado. Todo empresario inmerso en la referida lucha ${ }^{32}$ necesita la publicidad para atraer a posibles consumidores o usuarios.

Aunque la actividad publicitaria sea de libre ejercicio, al estar amparada por el derecho fundamental a la libertad de empresa, debe respetar unos límites o reglas para evitar transgredir la leal competencia y el buen funcionamiento del sistema económico de mercado en el seno del cual se asienta la publicidad (comercial). Por ello, se justifica la intervención del Derecho en esta actividad, protegiendo los valores y dignidad de las personas, así como defendiendo los legítimos intereses de los competidores, salvaguardando el correcto funcionamiento del Mercado, entendido como sistema económico ${ }^{33}$.

dominio, al no haber competencia, puede imponer los precios que más le interesen para alcanzar el máximo de beneficio (...)".

${ }^{31}$ La competencia (al igual que la publicidad comercial) es inherente al sistema capitalista. A colación cabe reseñar que en la Exposición de Motivos de la ya reformada Ley 3/1991, de Competencia Desleal, ya se indicaba que "(...) la institución de la competencia pasa a ser así el objeto directo de la protección" que le otorga dicha Ley, lo cual supone el establecimiento del marco legal regulador de la competencia en el sistema de economía de mercado.

32 "Se presume la finalidad concurrencial del acto cuando, por las circunstancias en que se realice, se revele objetivamente idóneo para promover o asegurar la difusión en el mercado de las prestaciones propias o de un tercero". Vid. art. 2.2 de la Ley 29/2009, de 30 de diciembre (BOE núm. 315, de 31 de diciembre de 2009), por la que se modifica el régimen legal de la competencia desleal y de la publicidad para la mejora de la protección de los consumidores y usuarios.

${ }^{33}$ Según DE LA CUESTA RUTE, "concebido el Derecho de la publicidad como el integrado por el mundo de lo jurídico que se refiere a las comunicaciones relativas a las transacciones de mercado, es obligado concluir que se enmarca en el campo (...) del Derecho (...) mercantil" -Vid. DE LA CUESTA RUTE, J. M. (2002), [op. cit., p. 40]-. La publicidad se encuentra inmersa -como si de una rama se tratara- en el Derecho Mercantil y, aunque los estatutos de las Comunidades Autónomas lo reflejen, éstas carecen de competencias sobre la citada actividad mercantil, reconociendo el Tribunal Constitucional al efecto que, en materia de publicidad, las debidas competencias son -exclusivamente- de orden estatal. A su vez, DE LA CUESTA RUTE afirma que "el error de hacer en 1988 de la publicidad la materia de un texto legal propio habría de tener malas consecuencias desde el punto de vista de las competencias autonómicas. (...) Naturalmente que el Tribunal Constitucional ha resuelto que la LGP es plenamente ajustada a la Constitución, no obstante ser una ley estatal. (...) El principio de unidad de mercado que informa nuestra Constitución según tiene declarado el Tribunal Constitucional ha de 
Según el DRAE, la publicidad -en su acepción más afín al presente estudio- es "la divulgación de noticias o anuncios de carácter comercial para atraer posibles compradores, espectadores, usuarios, etc." ${ }^{34}$. Por otro lado, en el Diccionario de Economía se entiende por publicidad el "conjunto de métodos que se utilizan para dar a conocer un producto en el mercado y estimular su demanda (...)"35.

En definitiva, aunque la obra publicitaria comenzara a adoptar el formato de cartel artístico a partir del s. XVI, lo cierto es que hubo que esperar hasta el s. XIX y principios del s. XX para asistir a su etapa de mayor esplendor. Al respecto, merecen una especial alusión, dada su repercusión internacional, los artistas franceses. Así, destaca, de un lado, la figura de Toulouse-Lautrec y sus coetáneos del siglo XIX y, de otro lado, ya en el siglo XX, O’Galop, creador del exitoso Bibendum.

\subsubsection{Toulouse-Lautrec y sus coetáneos decimonónicos}

Son muchos los movimientos artísticos que se observan durante el siglo XIX y principios del $X X$, como numerosos son los artistas que consiguieron aportar su particular estilo a los carteles publicitarios. Pero merecen una mención especial los cartelistas franceses, porque fueron ellos quienes mejor lograron unir arte (o, mejor, creación artística) y publicidad.

En general suele considerarse a Jules Chèret (1836-1932) como el padre del póster moderno. Gracias a su maestría en la técnica litográfica y a su evidente longevidad su contribución es muy extensa. Asimismo, Chèret ejerció cierta influencia sobre el postimpresionista Seurat (1859-1891), quien también representó figuras en movimiento.

A pesar de la densidad cartelista de la época, lo cierto es que artísticamente se consideraban subsidiarias. Sin embargo, con la entrada en escena de Tolouse-Lautrec (18641901), aquella apreciación cambió radicalmente. Su primer póster, Moulin Rouge (1891) anunciando el popular club de baile marcó una época, la Belle Epoque, al tiempo que encumbraba el cartel a la categoría de arte. El pintor frecuentaba los locales nocturnos donde observaba los personajes y sus gestos que luego plasmaba en sus creaciones. Al

prevalecer en todo caso, pues actúa como límite a las propias potestades de las Comunidades Autónomas" Vid. DE LA CUESTA RUTE, J. M. (2002), [op. cit., pp. 65-66]-.

${ }^{34}$ Cfr. AA.VV. (2001), Diccionario de la Lengua de la Real Academia Española, 22a ed., Espasa Calpe, S. A., Madrid, [op. cit., p. 1855].

${ }^{35}$ Cfr. TAMAMES GÓMEZ, R. (1989), Diccionario de Economía, 4a ed., Alianza, Madrid, [op. cit., p. 286]. 
respecto, destacan, entre otras, Divan Japonais (1892) y Aristides Bruant dans son cabaret (1892) publicitando sendos negocios.

En cierto modo, las composiciones de Tolouse-Lautrec sugieren economía de tintas, en el sentido que utiliza poca variedad de colores, aunque el acabado consiguió innumerables admiradores y sirvió de referencia a los artistas pre-expresionistas, así como a los que englobaron el denominado Art Nouveau ${ }^{36}$. En el cartelismo, fruto de dicho movimiento creativo, suele considerarse como máximo exponente a Alphonse Mucha (18601939) con su característico estilo florido en La dame aux camelias (1896), y apostando por ciertas reminiscencias del arte celta en Gismonda $(1896)^{37}$.

Al inicio del siglo XX la producción del póster se contrajo, en gran medida provocada por la muerte de Toulouse-Lautrec (1901) y por el abandono de Alphonse Mucha y de Jules Chèret, quien volvió a la pintura de caballete tras contar en su haber con una trayectoria creadora de más de mil carteles. Asimismo, París transfiere el testigo a Viena como capital de la cultura en Europa, y la fotografía comienza a utilizarse en la publicidad.

Como indicaba cierta información del antiguo Ministerio de Educación y Ciencia: “Lo cierto es que en el siglo XX el cartel pierde la mano de los artistas, aunque gana las posibilidades que proporcionan los avances electrónicos. La tecnología para crear cualquier tipo de soporte exterior ha dado alas al medio que sigue formando parte de la vida de las ciudades, aunque muchos suspiren por su pasado artístico. Hoy, el diseño publicitario ha tomado el relevo, consolidando la que es, sin duda alguna, la forma de publicidad, más antigua" 38 .

Ciertamente, tras la Primera Guerra Mundial (1914-1918), y antes de la Segunda Gran Contienda (1939-1945), el diseño gráfico de índole publicitaria se nutre de una nueva corriente artística, el designado $A r t-D e c O^{39}$, el cual se percibiría fuertemente influenciado por el futurismo ${ }^{40}$, el cubismo ${ }^{41}$, el expresionismo ${ }^{42}$ y el dadaísmo ${ }^{43}$. El principal cartelista de

\footnotetext{
${ }^{36}$ Cronológicamente, el estilo Art Nouveau (conocido en España como Modernismo) se sitúa principalmente en la última década del siglo XIX o hasta el estallido de la Primera Guerra Mundial (1914-1918).

${ }^{37}$ Fuente: Pinterest (2014).

${ }^{38}$ Fuente: Ministerio de Educación y Ciencia (2010).

${ }^{39}$ Se trata de un estilo industrialista que sugiere velocidad y energía.

${ }^{40}$ Corriente artística surgida en la Italia de principios del siglo XX, cuyo afán mecanicista aporta cierta sensación de movimiento a las figuras cubistas. Hasta tal punto el movimiento futurista exaltaba la belleza de la velocidad, que defendían que el rugido de un potente motor (o su representación gráfica) superaba el encanto de la Victoria alada de Samotracia (conocida escultura griega, referencia del arte tradicional de estilo clasicista).
} 
la época de entreguerras es el francés Cassandre ${ }^{44}$, quien con su estilo cubista elaboraba composiciones cuyo acabado recordaba a los óleos de Juan Gris.

Durante la segunda mitad del siglo XX la producción de carteles disminuyó en la mayoría de los países. Sin embargo, en Suiza el gobierno incentivó la industria del póster y, consecuentemente, surgió el denominado International Typographic Style, con sus predominantes elementos gráficos en tonos blancos y negros así como a la aplicación de esos colores en las fotografías utilizadas. En la década de los sesenta el Pop-Art recordaba, en cierto modo, los excesos florales del Art-Nouveau ${ }^{45}$.

\subsubsection{El siglo XX: $O^{\prime}$ Galop y sus contemporáneos}

En 1898, de la pluma del diseñador galo Marius Rosillon, cuyo pseudónimo es O’Galop, nació el personaje Bibendum, alegre embajador de la firma Michelín, aunque ciertamente, la idea de la famosa imagen corporativa no corresponde a él. Pues en una visita de los hermanos Michelín a la Exposición Universal y Colonial de 1894 celebrada en Lyon, mientras esperaban la presentación oficial de su producto original, se situaron frente al acceso principal del stand de su empresa donde el responsable había erigido dos altas pilas

\footnotetext{
Asimismo, cuando el protagonista de una determinada obra es el automóvil, la intención del autor es -inclusosugerir, de algún modo, el olor del volante. En definitiva, a los futuristas les fascina el maquinismo y sólo proyectan personas que ensalcen dinamismo, pues para ellos un cuerpo estático está muerto. En algunas ocasiones, como cuando participan en la ilustración de propaganda político-militar, de las cuales existen ejemplos visuales en International Poster (2010), entienden la acción como lucha o batalla, al tiempo que explícitamente- se manifiestan defensores del fascismo. La aplicación práctica de los fundamentos del futurismo a la publicidad se manifiesta -principalmente- en las obras de Fortunato Depero, quien conjugó su faceta de artista, de los nuevos conceptos estéticos, con la de publicista, gozando de una longeva relación de cooperación con la empresa Campari, quien ya en 1931 patrocinó la edición de un libro en el que el artista mostraba su ideario plástico así como su ideología fascista.

${ }^{41}$ Caracterizado por la geometría de formas, los artistas más relevantes que aplicaron esta técnica al cartel son Sonia Delaunay y Fernand Léger. La autora de "Mercado en el Miño" (1916), Sonia Delaunay, plasmó su visión mecanicista en muchos encargos publicitarios, incluso en el efectuado por la compañía Michelín. A principios de los años treinta experimentó un fructífero acercamiento a los luminosos de neón. Por su parte, Fernand Léger defendía anecdóticamente que las empresas fabricantes no deberían solicitar los servicios de los artistas para publicitar sus productos, pues -en su opinión- los salones anuales del automóvil, por ejemplo, son la mejor radiografía del Arte enmarcado en un evento publicitario. Asimismo Léger consideraba al cartel publicitario como un formato de expresión fresco y, por el contrario, a la pintura de caballete como algo caduco que ya no se vende bien. En el mismo sentido, concluye el estudio de Juan Carlos Gauli contenido en Arte vs. Publicidad (2010).

42 Hacia 1915 surgió en Weimar (Alemania) este movimiento contra la guerra que se caracterizaba por la economía de tintas. Los carteles expresionistas consistían en llamadas a la solidaridad, pues pretendían transmitir esa ideología pacifista.

${ }^{43}$ Considerando como verdadero arte al tradicional, la corriente dadaísta es revolucionaria en el sentido de presentarse como antiarte.

${ }^{44}$ Cassandre obtuvo numerosos encargos publicitarios desde que ganó el certamen de diseño de un póster para Michelín en 1919. Fuente: Arte vs. Publicidad (2010).

${ }^{45} \mathrm{Al}$ menos, en mi opinión.
} 
de neumáticos de distintos tamaños, a modo de columnas una a cada lado de la entrada del pabellón. Hasta tal punto dicho modo de colocación fue evocador para la imaginación de Edouard Michelín (1859-1940) que éste se dirigió a su hermano André en los siguientes términos: Regarde, avec des bras, cela ferait un bonhomme! ${ }^{46}$, [iMira, con dos brazos, parecería un noble!].

Posteriormente, aquel sonriente muñeco gordinflón sería realizado plásticamente y con gran maestría por $\mathrm{O}^{\prime} \mathrm{Galop}^{47}$, alcanzando una fama monumental.

Así pues, el vislumbramiento de Edouard Michelín ${ }^{48}$ se adelantaba en el tiempo a las figuras tubulares de Fernand Léger, con una imagen que simbolizaba el espíritu de la nueva época: el maquinismo.

La personificación de los objetos, llevada a cabo en las creaciones publicitarias de principios del siglo XX, desembocaría, años después, en representaciones de la mecanización del cuerpo humano. En efecto, en los primitivos carteles de Michelín la encarnación de los neumáticos daría paso, años después, a la adopción del movimiento.

Por tanto, aunque en sus inicios, las creaciones publicitarias donde aparece Bibendum, cronológicamente pertenecieran al Art-Nouveau, posteriormente evolucionarían con los tiempos, pasando por los cauces del Art-Deco, etc., hasta alcanzar los tratamientos electrónicos más actuales. Consecuentemente, hoy en día es considerado un icono artístico de la publicidad. En definitiva, el logro principal de ésta obra publicitaria ${ }^{49}$ es el haber

\footnotetext{
${ }^{46}$ Según apunta DARMON, O. (1997), Le grand siècle de Bibendum, Editions Hoëbeke, Paris, [op. cit. p. 22]. A mayor abundamiento, en la antigua fábrica instalada en la ciudad de Clermont-Ferrand (perteneciente a la región francesa de Auvernia), actual sede principal de la marca, los guías turísticos explican que, en aquella ocasión, Edouard Michelín tomó prestadas las gafas de su hermano y las colocó, a modo de ojos, en el segundo neumático de arriba, al objeto de convencerle de su apreciación.

${ }^{47}$ Es sabido que confiaron en O'Galop porque una de sus creaciones transnacionales les había cautivado, en concreto el cartel elaborado para la cervecería Gambrinus ubicada en la ciudad de Munich, donde se muestra un fornido bávaro alzando su jarra bajo el lema Nunc est bibendum [Y ahora bebamos] expresión en latín utilizada ya en la época de la civilización romana por el poeta Horacio en uno de sus versos.

${ }^{48}$ Se cuenta que antes de realizar los correspondientes esbozos de Bibendum, Edouard Michelín ya poseía vocación artística. No en vano, tras completar sus estudios de Derecho, había asistido a varios cursos en la Escuela de Bellas Artes de París. Posteriormente, decidió entrar a formar parte del negocio familiar (del que luego llegaría a ser el primero de abordo y que originariamente fabricaba componentes para bicicletas, cuyo producto estrella no eran los neumáticos, sino las zapatas de freno reconocidas como las más silenciosas).

${ }^{49}$ Asimismo existen numerosas obras derivadas, pues Bibendum consiguió el papel protagonista de incontables creaciones de autores nacionales y extranjeros, por ejemplo en España, pinturas de Javier Mariscal, esculturas de Antonio Gaudí y de Salvador Dalí, así como narraciones de Ramón Gómez de la Serna, entre otros. En consecuencia, considero que actualmente parece apropiado calificar a Bibendum como mito publicitario del Arte.
} 
proyectado un logotipo que perdura en el tiempo, hasta el punto de haber sido galardonado con el preciado título de mejor logo del siglo XX. Ciertamente, desde sus orígenes, Bibendum está presente en la vida cotidiana de personas de todas las generaciones, en los cinco continentes, traspasando cualquier frontera social. Pues los hermanos Michelín, auténticos visionarios de la publicidad, consiguieron introducir sus productos en la conciencia colectiva ${ }^{50}$. Aunque la verdadera finalidad del esfuerzo llevado a cabo era contribuir a la creación de un mercado futuro en el que la población conduciría coches.

Por último, como contemporáneo de O’Galop, cabe destacar, en mi opinión, a George Massiot Brown, quien en el año 1928 tuvo la osadía de pintar la misteriosa figura del emblemático Don, imagen de la marca Sandeman ${ }^{51}$. Se trata de todo un símbolo en el país luso y combina la capa negra característica de los estudiantes universitarios portugueses y el sombrero español. Este enigmático personaje ha conseguido que Sandeman sea la marca de vinos de Oporto más representada a nivel mundial. También, cabe destacar que fue la primera bodega en marcar sus barriles "a hierro", inicialmente con las siglas GSC (George Sandeman Company) y, posteriormente, con su reconocido y prestigioso icono.

\subsubsection{Las primeras creaciones publicitarias elaboradas en España}

Conocida la tradicional utilización generalizada del pregonero en España como en otros países -y remontándose su figura a la época de la antigua civilización mesopotámicaquizá el elemento más representativo y diferenciador de la ancestral publicidad española en el mundo sean los toros ${ }^{52}$.

A finales del siglo XVII, los orígenes del periodismo permitieron la aparición de anuncios por palabras, y prueba de ello son los publicados en La Gaceta de Madrid de 1691.

\footnotetext{
${ }^{50}$ Antiguamente, cuando apenas había coches, ya se asociaba al muñeco de Michelín con mapas de carreteras, guías turísticas y gastronómicas. Asimismo, es frecuente la participación de la compañía en el patrocinio de eventos deportivos, lúdicos y festivos, así como en el mecenazgo de certámenes culturales.

${ }^{51}$ A pesar de que, en términos generales, la marca Sandeman se asocie con Portugal, realmente no fue fundada en el país luso sino en Gran Bretaña. Además, sigue contando con sus importantes bodegas jerezanas. A mayor abundamiento, el escocés George Sandeman fue quien fundó en 1790 la compañía dedicada a comerciar, desde Londres, vinos de Portugal y España. Tan solo cinco años después ya estableció una filial en Cádiz, donde producía y comerciaba vinos de Jerez. Y, tal como explican los guías turísticos de la reconocida firma en su sede porteña de la localidad de Gaia, (y, por supuesto, vestidos de “Don"), en 1811 Sandeman compró unos viñedos en dicha villa para producir y comerciar vinos de Oporto.

52 De ahí que, a posteriori, se dedique un subapartado al efecto.
} 
Asimismo, desde mediados del siglo XIX el establecimiento de agencias publicitarias $^{53}$ no cesó de aumentar. En este sentido, de forma -prácticamente- unánime, se admite que el cartelismo facilitó el nacimiento de la publicidad moderna. No obstante, la etapa dorada del cartelismo español llegó con retraso y se concentró en tan solo tres décadas (1890-1920), siendo ejemplos inequívocos de esa época los anuncios de Anís del Mono, así como los de Codorniu, destacando la obra de Ramón Casas, vinculada al Art Nouveau o Modernismo. En cualquier caso, la dilatada aportación del mundialmente conocido pintor malagueño Pablo Picasso, que se prolongó más allá de las tres décadas apuntadas, merece una especial alusión ${ }^{54}$.

Posteriormente, la Guerra Civil (1936-1939) supuso el mayor despliegue publicitario hasta la fecha, aunque -ciertamente- en este caso el cartelismo adquiría un nuevo enfoque: la propaganda 55 .

\subsubsection{Los motivos taurinos}

El primer cartel taurino data del año 1737 y anunciaba la celebración de dos corridas de toros en la plaza instalada en el distrito de Dehesa de la Villa (Madrid), a beneficio de los Reales Hospitales.

Por entonces la técnica de impresión utilizada en las composiciones taurinas se circunscribía a la tipografía ${ }^{56}$, pues la litografía comenzó a manejarse en el año 1830.

De otro lado, por su importancia ${ }^{57}$, merece una mención especial el popular Toro de Osborne. Su gestación se remonta al año 1956, cuando el diseñador gráfico Manuel Prieto, empleado de la agencia publicitaria Azor, encontró la silueta y el soporte perfectos. Así nació este imponente guardián de las carreteras.

En el año 1957 vio la luz el primer Toro, el cual se emplazó en Cabanillas de la Sierra (Madrid). Este enorme cartel construido con paneles de chapa sobrepasa los catorce metros

\footnotetext{
${ }^{53}$ Ciertos estudios constatan que La Correspondencia de España, fundada por Manuel de Santa Ana en 1853 fue la primera agencia de publicidad en nuestro país. Fuente: Arte vs. Publicidad (2010).

${ }^{54} \mathrm{~A}$ tal efecto, se dedica el correspondiente subepígrafe en el presente trabajo.

${ }^{55}$ Dicho carácter propagandístico es observable en numerosos ejemplos del cartelismo elaborado durante la Guerra Civil, los cuales se muestran en UGT (2010).

${ }^{56} \mathrm{Si}$ bien es cierto, se trataba de carteles tipográficos a los que -en algunas ocasiones- se les añadía una ilustración en xilografía. En este sentido, existe unanimidad en considerar como cartel más antiguo, con texto e imagen, al de una corrida de toros en Sevilla hacia el año 1763.

${ }^{57}$ Dado que, incuestionablemente, más que simbolizar la propia marca Osborne, se ha convertido en auténtico emblema de España.
} 
de altura, superando ligeramente las cuatro toneladas de peso. Actualmente existen noventa ejemplares distribuidos por toda la geografía nacional.

Por su parte, el Tribunal Supremo indultó de su retirada de las carreteras a este hito del diseño publicitario, considerándolo de interés cultural ${ }^{58}$. En definitiva, se trata de un símbolo universal identificador de la cultura española.

\subsubsection{La dilatada aportación de Picasso}

Posiblemente, la exposición de cartelistas franceses celebrada en la Sala Parés de Barcelona en 1896, influenciara la época catalana del malagueño, reuniéndose con otros artistas modernistas en la cervecería barcelonesa Els Quatre Gats. En este sentido, marcado por el nuevo arte publicitario, Picasso proyectó el diseño de la carta de menús de dicho local en 1898, y dos años después inauguró su primera exposición ${ }^{59}$.

Como es bien sabido, ya en 1911 Picasso es considerado el primer artista que incorporaba en muchos de sus lienzos, a modo de collage, fragmentos de publicidad (en su mayoría, procedentes de periódicos). Es lo que se conoce como cubismo sintético ${ }^{60}$. A mayor abundamiento, en 1912 perfila la obra "Botella de Vieux Marc, vaso y periódico" en la cual agrega una fracción del anuncio de estilógrafos $O h$ to $^{61}$, concretamente la parte del slogan que aludía a los cubistas, literalmente: Pour vous etrennes. Cubistes ou non, offrez carrément un Ohto [Para sus compromisos. Cubistas o no, regalen un Ohto].

Asimismo, en 1915, sin existencia alguna de encargo previo por parte de la empresa Anís del Mono, llevó a cabo un óleo ${ }^{62}$ donde el indudable motif era publicitar la conocida marca.

Posteriormente, en 1945 con cientos de litografías en su haber, supo aprovechar el último resurgimiento del cartelismo parisino. Picasso continuó transmitiendo su huella, incentivado por el impresor Mourlot, quien le ofreció su taller ubicado en la capital francesa. De esa época datan numerosos carteles de tinte propagandístico, supuestamente fomentados -al menos, en parte- por su reciente afiliación al Partido Comunista.

\footnotetext{
58 Vid. STS, de 30 de diciembre de 1997.

59 Para ampliar esta información, consúltese la obra bibliográfica: AA.VV. (1995), Picasso y Els Quatre Gats, Lunwerg Editores, Barcelona.

60 Anteriormente, en virtud del cuadro "Las señoritas de Avignon" (1906), también se le había atribuido el nacimiento del denominado cubismo analítico.

${ }^{61}$ Aparecido en el diario Le Journal en repetidas ocasiones durante ese mismo año.

62 Incluso el artista tituló dicha creación como "Botella de Anís del Mono, copa y naipe".
} 
En definitiva, el artista elaboró numerosos carteles publicitarios de diversos productos. Al mismo tiempo recibía encargos para imprimir su personalidad en anuncios de eventos relacionados con el ocio y espectáculos de la época.

\section{Epílogo}

La actividad publicitaria es el resultado de una evolución de la realidad social, económica y tecnológica que se remonta a tiempos antiguos. $\mathrm{Y}$, a través del método histórico, podemos aproximarnos a lo que hoy es la obra publicitaria.

Posiblemente merecería un aparte continuar con un epígrafe del siguiente orden: "del cartelismo y el poster a la era digital", sin embargo, considero que el mismo se situaría fuera del objeto del presente estudio. No así las rúbricas señaladas con anterioridad, pues éstas justifican que ya desde tiempos pretéritos la obra publicitaria ha mostrado un inequívoco carácter artístico, con lo que, se refuerza la presencia (al menos, de modo implícito) de este tipo de creación en la enumeración que de obras protegidas por el Derecho de Autor dispone el art. 10 LPI.

Con todo, parece oportuno proponer, de lege ferenda, una eventual reforma del Texto Refundido de la LPI que incluya una referencia expresa a la obra publicitaria (como sí hace, sin embargo, en relación con la obra cinematográfica).

\section{REFERENCIAS BIBLIOGRÁFICAS}

AA.VV. (2001), Diccionario de la Lengua de la Real Academia Española, 22ª ed., Madrid: Espasa Calpe, S.A.

AA.VV. (1995), Picasso y Els Quatre Gats, Barcelona: Lunwerg Editores.

ALDEA.NET (2010), Información relativa a la Propiedad Intelectual ofrecida por la agencia Aldea.net, disponible en https://aldea.net/html/derecho autor.html, consultado en mayo de 2016.

ARTE VS PUBLICIDAD (2010a), Referencia a la expresión oral como principal medio de comunicación comercial, disponible en: https://artevspublicidad.blogspot.com, consultado en mayo de 2016.

ARTE VS PUBLICIDAD (2010b), Referencia a la imprenta en la elaboración de creaciones publicitarias, disponible en: https://artevspublicidad.blogspot.com, consultado en mayo de 2016.

ARTE VS PUBLICIDAD (2010c), Referencia al cartel publicitario como un formato de expresión fresco en contra de la caduca pintura de caballete. En este sentido, concluye el estudio de Juan Carlos Gauli contenido en https://artevspublicidad.blogspot.com, consultado en mayo de 2016.

ARTE VS PUBLICIDAD (2010d), Referencia a Cassandre, información disponible en: https://artevspublicidad.blogspot.com, consultado en mayo de 2016. 
ARTE VS PUBLICIDAD (2010e), Ciertos estudios constatan que La Correspondencia de España, fundada por Manuel de Santa Ana en 1853 fue la primera agencia de publicidad en nuestro país, https://artevspublicidad.blogspot.com, consultado en mayo de 2016.

AVAY (2015), Imágenes de Sandeman, disponibles en: https://ayay.co.uk, consultado en diciembre de 2015.

AYUNTAMIENTO DE BARCELONA (2014), Cartel publicitario de la cervecería "Cuatro Gatos" elaborado por Picasso en 1898, disponible en https://barcelona-on-line.es, consultado en mayo de 2014.

BIOGRAFÍAS Y VIDAS (2010), Referencia al arqueólogo francés Jacques de Morgan, disponible en: https://biografiasyvidas.com, consultado en mayo de 2014.

DE LA CUESTA RUTE, J. M. (2002), Curso de Derecho de la Publicidad, Pamplona: Eunsa.

DARMON, O. (1997), Le grand siècle de Bibendum, Paris: Editions Hoëbeke.

EBANATAW (2014), Fotografía del Código Hammurabi, imagen disponible en: https://ebanataw.com.br, consultado en mayo de 2014.

GOLEM INDISPENSABILE (2014), Cartel publicitario de la marca Campari, obra de Fortunato Depero (1931), disponible en: https://golemindispensabile.it, consultado en mayo de 2014.

HCIVILIZACIONES (2011), Referencia a los mercados en la Grecia clásica, disponible en: https://historiadelascivilizaciones.com, consultado en mayo de 2013.

HISTORIA CLÁSICA (2007), Información sobre el poderoso rey Hammurabi, disponible en https://historiaclasica.com, consultado en octubre 2013.

HISTORIANG (2010), Información sobre el Código Hammurabi, disponible en: https//historiang.org, consultado en mayo de 2013.

HISTORIA PUBLICIDAD (2007), Referencia a las marcas en la segunda mitad del s. XIX, disponible en: https://lahistoriadelapublicidad.com, consultado en mayo de 2012.

HISTÓRICO DIGITAL (2010), Referencia al término de la Prehistoria y al inicio de la Historia, disponible en: https://historicodigital.com, consultado en octubre de 2010.

IMPERIO ROMANO (2012), Referencia a los pregoneros en Grecia y Roma, disponible en: https://imperioromano.com, consultado en mayo de 2012.

INTERNATIONAL POSTER (2010), Referencia a la ilustración de propaganda político-militar, existen ejemplos visuales en https://internationalposter.com, consultado en octubre de 2010.

LADY TRAP EN LOS TOROS (2014), Primer cartel taurino de la Historia, disponible en https://ladytrapenlostoros.blogspot.com, consultado en mayo de 2014.

MICHELIN BOUTIQUE (2014), Cartel publicitario de la marca Michelín, obra de O'Galop (1898), disponible en: https://michelin-boutique.com, consultado en mayo de 2014. 
MINISTERIO DE EDUCACIÓN Y CIENCIA (2010a), Información sobre el primer periódico de anuncios por palabras precursor de la publicidad a domicilio, disponible en: https://tv mav.cnice.mec.es, consultado en mayo de 2010.

MINISTERIO DE EDUCACIÓN Y CIENCIA (2010b), Información sobre el cartel publicitario en el s. XX, en: https://recursos.cnice.mec.es/media/publicidad/index.html, consultado en mayo de 2010.

MONOGRAFÍAS.COM (2012), Referencia a los comienzos de la publicidad en la civilización griega, disponible en: https://monografias.com, consultado en mayo de 2012.

PINTEREST (2014), Referencia a los carteles publicitarios obra de Alphonse Mucha, información disponible en: https://pinterest.com, consultado en mayo de 2014.

PUBLICIDAD IDÓNEOS (2012), Referencia al anuncio publicitario más antiguo que se conserva, tal y como indica la información titulada "Breve historia de la publicidad", disponible en: https://publicidad.idoneos.com, consultado en octubre de 2012.

REPROARTE (2014), Carteles publicitarios obra de Toulouse-Lautrec en 1892, disponible en: https://reproarte.com, consultado en mayo 2014.

TAMAMES GÓMEZ, R. (1989), Diccionario de Economía, 4ạ ed., Madrid: Alianza.

TECTÓNICA (2014), Lienzo de carácter publicitario de la marca Anís del Mono, obra de Picasso (1915), disponible en: https://tectonicablog.com, consultado en mayo de 2014.

TIME RIME (2010), Referencia a la primera agencia publicitaria de la historia del marketing, disponible en: https://museon.timerime.com, consultado en mayo de 2013.

TOUS LES CADEAUX (2014), Cartel publicitario obra de Picasso (hacia 1945), disponible en https://touslescadeaux.com, consultado en mayo de 2014.

UGT (2010), Ejemplos de cartelismo elaborado durante la Guerra Civil, disponible en: https://ugt.es/ugtpordentro/guerracivil/carteles.htm, consultado en mayo de 2010.

VANITY FAIR (2014), Imagen del toro de Osborne, disponible en: https://revistavanityfair.es, consultado en mayo de 2014.

WAHOO ART (2014), Lienzo con carácter publicitario de los estilógrafos de la marca Ohto, obra de Picasso (1912), disponible en: https://es.wahooart.com, consultado en mayo de 2014.

WALKER, C. B. C. (2004), Cuneiform, Londres: British Museum Press.

ZOECHOUETTE (2014), Carteles publicitarios de la marca Michelín, disponible en: https://zoechouette.free.fr, consultado en mayo de 2014. 